\title{
Student evaluations of a year-long mentorship program: A quality improvement initiative
}

\begin{abstract}
Mentoring is an important teaching-learning process in undergraduate nursing curricula. There are relatively few studies specifically evaluating nursing students' perceptions of mentorship. In the period 1999 - 2002, thirty-nine students were mentored during a year-long program. This descriptive, exploratory study used a quality improvement framework informed by the Deming Cycle of Plan, Do, Check and Act (Deming 1982) to evaluate the mentorship program from the students' perspective. Information was gathered through surveys, focus group discussions and interviews and analysed to identify themes of responses. Identified themes were 'The doing of nursing', 'The thinking of nursing' and 'Being a nurse'. The study confirmed the value of mentorship in undergraduate nursing and highlighted the importance of skill competence as a basis for professional role identity by graduating students. The benefits of mentorship were derived from a long term, supportive relationship with the same registered nurse who was committed to the student's professional development.
\end{abstract}

Key words: Clinical nurse education, mentorship program, mentors, mentees, student nurse, Deming Cycle 


\section{Introduction}

Mentoring has been used in nurse education to enhance practice-based learning since the 1980s and has received wide spread adoption particularly in the UK with the implementation of Project 2000 (Andrews \& Wallis 1999). However, there is confusion about the definition and operationalisation of the term (Brammer 2002). Ehrich et al. (2002) in their critical review of the literature identified that many terms are used synonymously to identify support persons without clear definitions. In nursing the terms 'preceptorship', 'mentoring' and 'buddying' are often used to mean the same role but enacted differently. Ehrich et al (2002, p.255) defined mentoring as “...a personal, helping relationship between a mentor and mentee/protégé that includes professional development and growth and varying degrees of support". It differs from preceptorship in terms of duration, intensity, scope of support and development. This definition was adopted for the purposes of the present study which focuses on mentorship.

This paper reports on the evaluation of a hospital quality improvement initiative aimed to provide opportunities for undergraduate nurses to integrate theory and practice, and facilitate professional growth and development through mentorship. This initiative was evaluated according to the Deming Cycle (Deming 1982), a continuous four-step process improvement tool of Plan, Do, Check, and Act (PDCA). The PDCA Cycle provides a useful framework for implementing and evaluating quality projects and has been used widely in the health care area as a process improvement tool (Manfredi et al. 2003). According to the Deming Cycle the first step required our team of nurse educators, clinicians, administrators and nurse academics to identify how to improve student learning through the provision of a supportive collaborative clinical environment. A needs assessment was conducted with relevant staff of the hospital, university school of nursing, and students and resulted in the development and implementation of a mentorship program in 1999. 
The mentorship program involved final year nursing students being mentored by experienced registered nurses at the hospital to provide clinical practice and professional support during their last two semesters of study. Students submitted written expressions of interest to be involved in the program. Similarly, registered nurses lodged an application with hospital administration. Students and mentors were then paired during a meeting where program aims and expectations of mentors and mentees were outlined. Students agreed to arrange appointments with mentors at times convenient to both, complete a diary each week in relation to program and clinical activities, attend focus group discussions, and prepare documentation and information before appointments with mentors. Students had access to their mentors not only during university planned clinical practice (equivalent of ten weeks maximum) but also at other times over the duration of two semesters, as negotiated with their mentors. Participants in the program were covered by the existing clinical practice insurance policy of the University under its clinical learning provisions.

Thirty-nine students were mentored from 1999 - 2002. The frequency and duration of contact between students and their mentor varied. The majority of students reported accessing their mentors on a regular basis, the average being one to three hours per week throughout the year. Some students also gained casual work at the hospital as assistants in nursing as an unplanned consequence of the program. These students were therefore able to access their mentors more frequently.

Quality assurance information about the perceived effectiveness of the program was collected through various means. This paper reports on an analysis of students' perceptions of the mentorship program and its influence on their learning and professional growth from the information sought in the third phase (Check) of the Deming Cycle. Some improvements to the mentorship program have occurred over time given the cyclical nature of the Deming Cycle. These included early identification of mentees accepted into the program, revisions of 
written information provided to mentees and mentors on their respective roles and expectations in relation to the program, and the inclusion of a series of information sessions for mentors about academic course content being undertaken by students. Mentors therefore had a good understanding of expected learning outcomes for students.

\section{Literature Review}

There is considerable agreement on the benefits of mentorship. In their review of 159 studies, Ehrich et al. (2002, p.257) identified the six most frequently cited positive outcomes for mentees as:

· support/empathy/encouragement/ counseling/ friendship;

- help with learning strategies/ subject knowledge/ resources;

- discussion/sharing ideas/ problem solving/advice from peers;

. feedback/positive reinforcement, increased confidence; and,

- career affirmation/ commitment.

The most frequently cited problem for mentees was lack of time with mentors (Ehrich et al. 2002). Although the review was not specifically related to mentoring in nursing, it provides an overview of important issues for mentees in any context.

The majority of recent research on mentoring in nursing has emanated from the United Kingdom in response to Project 2000. Studies have explored students' perceptions of mentors (Chow \& Suen 2001, Watson 1999), the roles and responsibilities of mentors (Watson 2004, Pulsford Boit \& Owen 2002, Gray \& Smith 2000, Neary 2000, Hayes \& Harrel 1994) and relationships between mentors and students (Andrews \& Roberts 2003, Spouse 2001, Andrews \& Chilton 2000). Brammer (2002), however, identified variability in how "mentoring" was operationalised and noted relatively little evaluation of nurse mentorship programs. 
Our search of the relevant literature identified only a limited number of studies that considered the student nurse perspective of a mentorship program. One Australian study surveyed 78 second year students on satisfaction with a fourweek mentorship scheme (Lo 2002). Nearly all students (96\%) rated the scheme "good to excellent". Positive aspects included continuity of practical experiences, developing nursing skills that enhance confidence, improving communication and reporting skills, working on a variety of shifts, working as a team member and, having respected RNs as mentors (Lo 2002, p.30). Students reported that mentorship provided opportunities to integrate theory and practice and learn from good role models in terms of clinical and professional practice. In this study, students were placed with a "mentor" for two, two-week placements, and they worked alongside the same person "if practical".

A multi-phase study in Hong Kong (Chow \& Suen 2001; Suen and Chow 2001) investigated student perceptions of mentorship according to a definition that encompassed five aspects - assisting, befriending, guiding, advising and counseling. Students gave particular emphasis to the practical roles of assisting and guiding their skill development (Chow \& Suen 2001). This interview data was then used as the basis for a survey tool to evaluate the program. The survey found that students' positive perceptions were associated with the level of satisfaction with their mentors. Suen and Chow (2001) attributed the change in student perceptions over time to mentors being more prepared and having a better understanding of role expectations. In this program, two students were supervised and mentored during their placement by a clinician appointed as an honorary clinical instructor. Possibly as a consequence of this structure, students reported less satisfaction with the 'befriending' aspects of mentorship, and reported being treated like 'guests' by mentors and the ward team. The authors recommended further research on the mentee-mentor relationship to develop a comprehensive understanding. 
Key characteristics of effective mentorship vary across studies. Students in a qualitative study in the UK reported that effective mentors provided more opportunities to bring theory and practice together than other clinicians (Spouse 2001). In this mentorship scheme, students accessed a number of mentors during planned clinical placements across different clinical sites in different geographical areas. In another longitudinal grounded theory study in the UK, ten nursing diploma students linked effective mentorship to professional socialization (Gray \& Smith 1999). Students identified that mentors promoted the development of psychomotor skills essential for practice, holistic thinking about care, and a clearer sense of the reality of being a nurse as part of the professional socialization process.

Overall, there are relatively few studies specifically evaluating nursing students' perceptions of mentorship programs. Although the literature consistently identifies "mentorship" programs as valuable in nursing, the majority of studies evaluated mentoring offered during planned clinical placements. It could be argued that this arrangement more closely reflects preceptorship where the "support role is of shorter duration and more focused on the specifics of the job" (Ehrich et al. 2002, p.255). In contrast, the present paper considers students' perceptions of a year-long mentorship program that functioned in addition to designated clinical placement periods.

\section{Research design and method}

The design for the evaluation of this mentorship program was informed by the PDCA quality improvement framework (Deming 1982). This paper aims to contribute to the dissemination of quality improvement initiatives, which often go unreported in the wider sphere of practice. Bloor (1999) argued the importance of evaluating and disseminating the effectiveness of organisational quality management processes to improve practice. 
The third step of the Deming Cycle requires that information be gathered to determine if the implemented plan has been effective. Information about the mentorship program from students was routinely collected from focus group interviews facilitated by the hospital-based Nurse Educator (Staff Development) twice a year, as well as anonymous open-ended questionnaires administered at the end of each year-long program. Thirty-nine students were involved in the program from 1999 - 2002. Evaluations of quality initiatives relating to professional activities are standard practice in the participating organization and are published in quality assurance reports. Names of respondents were not required.

Items on the survey questionnaire were derived from a literature review and clinical experience of the project team. Questions focused on perceived strengths and weaknesses of the program, adequacy of mechanisms to support the program and personal and educational benefits. Face and content validity were enhanced through the use of a reference group including nurse educators, registered nurses and academics, who reviewed the questionnaire. The panel recommended minor adjustments to the wording and structure of some questions for clarity. Student responses gathered in these various ways were then classified into specific themes by analyzing the content of responses, clustering similar data, and assigning them to a theme that best described the central meaning of the clustered data.

\section{Findings}

The findings are presented as a discussion of the three themes that emerged from the analysis of the data. These themes are: 'The doing of nursing', 'The thinking of nursing' and 'Being a nurse'.

\section{The doing of nursing}

The majority of students identified that the mentorship program was "valuable" and provided opportunities to be guided and assisted in the development of 
psychomotor skills. Although the mentorship relationship involved more than just the development of psychomotor skills, many students viewed the visible 'doing' work of nursing as an important aspect of providing patient care and thus important to their overall professional development. Lawler (1991, p.30) asserts, "what remains unchanged and unchanging [in the professional view] is that nurses are fundamentally concerned with the physical care and comfort of patients". Given that participants were final year students, the emphasis on certain complex psychomotor skills was predictable. Medication administration including intravenous and intrathecal, fluid management, urinary catheterisation, complex wound care, and performing electrocardiographs were the most frequently cited honed clinical skills.

Previous research identified that students find clinical skills or procedures challenging or anxiety provoking (White 2003, Cooke 1996). Students in the present program reported that mentorship enhanced confidence in their ability to safely and competently perform a wide range of psychomotor skills thus reducing this anxiety and positively influencing their overall professional growth. One student reported,

My mentor... always found something for me to do in order to build up my self-confidence, more hands on practice in performing clinical skills

So the emphasis was not just the development of psychomotor skills but also building of self-confidence and professional growth. Mentors, who provided opportunities for practice, were also perceived to facilitate the broader professional development of students through clinical competence. White (2003) found that students acknowledged the importance of clinical skill development for self-confidence in the clinical environment and argued that until students feel confident they cannot focus on holistic care. 
The ability to access mentors not just during university planned clinical placements but as learning needs arose during the semester, was instrumental in students' clinical skill development. Students reported that the individual attention of an identified mentor enabled them to initiate contact through telephone calls or e-mails to inform mentors what they were learning on-campus. Similarly, mentors also initiated contact with students when good learning opportunities presented themselves in the clinical setting. The benefits of such year-long mentorship relationships are rarely reported in the literature.

\section{The thinking of nursing}

It was clear from students' responses that the mentorship program achieved its overall objective of providing opportunities for the integration of theory and practice. The mentorship program provided students with opportunities to identify their practice learning needs, and negotiate strategies to meet these needs with mentors who were experienced and knowledgeable practitioners. In this way, mentoring enabled students who had theoretical knowledge to relate and apply this to their practice. Student evaluations identified that mentorship facilitated "thinking" practices such as prioritizing, making judgments about patient situations and care needs, managing their time, problem-solving and critiquing their own work. The following written comments by students give the flavour of responses:

Allowed me to develop critically thinking skills and nursing process skills.

Allowed me the opportunity to reduce the theory practice gap.

Spouse (2001) argued that the promotion of students' integration of theory and practice through mentorship is dependant on the learning environment and resources. Activities organized to meet identified student needs assist them to apply theoretical knowledge to practice (Spouse 2001). This process is reflected in the present mentorship program, as students were able to access their mentors when learning needs arose as a result of on-campus learning sessions 
and not just during planned placements. An intense, supportive, one-to-one relationship developed between students and mentors over an extended period of time and was beneficial in helping students meet their overall needs for professional growth and development.

\section{Being a nurse}

A major benefit of the program from the student perspective was enabling them to "put it all together" to not only provide holistic and effective care, but to be "a nurse" in terms of all that this entails. In this way students were involved in the process of professional socialization where they learn the culture of nursing (De Bellis et al. 2001). Students went to great lengths to describe the benefits of the mentorship program in preparing them for practice as registered nurses. Students identified that this professional socialization process included being valued as a team member, being familiar with the hospital environment, increased understanding of how different health professionals work together, obtaining career advice, gaining a clearer understanding of the roles and responsibilities of a registered nurse, and gaining a sense of the reality of nursing. One student identified the benefits as:

Development of working relationships, integration into team environment and ward environment, encouragement and exposure to various new learning experiences, insight into the professional registered nurses role, work as a team and consult with a team, responsibilities and duties of a RN

The mentorship program provided opportunities for students to develop professional identity. From the outset, participating students were required to express interest through a written application and comply with pre-determined professional requirements. According to Secrest et al. (2003), professional socialization is an active process. The commitment of students to the educational experience in the present program contributed to enhanced learning opportunities that increased knowledge, skills and confidence. White (2003) 
confirms that as students gain confidence in the clinical environment they start to identify themselves as nurses. Our results are in contrast to those of Suen \& Chow (2001) where students reported dissatisfaction with this aspect of the mentor role, and may be a reflection of differences in program structure and processes. In the present study students reported a strong sense of team membership and acceptance in the clinical environment.

\section{Conclusion}

This study adds to our understanding of the role and nature of mentoring that has not been identified in previous literature. Although the emphasis on the 'doing of nursing' has been consistently reported in previous studies, differences were identified in terms of professional socialisation and the integration of theory and practice. Offering a year-long mentorship program allowed for a more enabling relationship to be formed between student and registered nurse that facilitated professional development and growth as well as a sense of belonging and identity. Mentoring facilitates practice-based learning by assigning a student to practice with a mentor who is an experienced clinician and takes a particular interest in the personal and professional development of the student. We would argue that previous reported models of mentorship did not adequately foster the relationship aspect of the role. Mentoring is a learning and developmental process that assists students' achievement of competencies, orientation to the clinical role, and personal and professional accomplishment (Ehrich et al. 2002). The accomplishment of such goals requires time and commitment that cannot be achieved in short placements.

Information gathered over a four-year period as part of the Deming Cycle of quality improvement in our study consistently identified that students perceived mentorship as a valuable education and professional development experience. It provided opportunities for practice-based learning through connecting and sharing with experienced clinicians. Mentoring in nursing is usually associated with planned clinical placements however this program allowed students to 
access mentors over an extended period and as learning needs arose. The program enabled students to gain confidence in their technical clinical skills, integrate theory and practice and develop a professional identity as nurses. In this way, students perceived they were well prepared for the transition from student to registered nurse. Although the number of students involved in this initiative is not large the findings suggest that the development of a year-long mentorship program for final year nursing students is valuable in preparing them for the workplace. The success of this initiative has ensured its continued implementation and is viewed as a worthwhile long-term investment by the organization and university for quality clinical learning. 


\section{References}

Andrews M, Wallis M 1999 Mentorship in nursing: a literature review. Journal of Advanced Nursing 29: 201-207

Andrews M, Chilton F 2000 Student and mentor perceptions of mentoring effectiveness. Nurse Education Today 20: 555-562

Andrews N, Roberts D 2003 Supporting student nurses learning in and trough clinical practice: the role of the clinical guide. Nurse Education Today 23: 474 481

Bloor G 1999 Organisational culture, organizational learning and total quality management: A literature review and synthesis. Australian Health Review 22: $162-179$

Brammer J 2002 Understanding the role of the registered nurse in student learning. Unpublished PhD thesis. Queensland University of Technology, Brisbane, Australia

Chow F, Suen L 2001 Clinical staff as mentors in pre-registration undergraduate nursing education: students' perceptions of the mentor's roles and responsibilities. Nurse Education Today 21: 350-358

Cooke M 1996 Nursing students' perceptions of difficult of challenging clinical situations. Journal of Advance Nursing 24: 1281-1287

De Bellis A, Longson D, Glover P, Hutton A 2001 The enculturation of our nursing graduates. Contemporary Nurse 11: 84-94 
Deming W E 1982 Quality, productivity and competitive position. Massachusetts Institute of Technology, Cambridge.

Ehrich L, Tennent L, Hansford B 2002 A review of mentoring in education: Some lessons for nursing. Contemporary Nurse 12: 253-264

Gray M, Smith L 2000 The qualities of an effective mentor from the student nurse's perspective: findings from a longitudinal qualitative study. Journal of Advanced Nursing 32: 1542-1549

Hayes E, Harrel C 1994 On being a mentor to nurse practitioner students: The preceptor-student relationship. Nurse Practice Forum 54: 220 - 226

Lawler J 1991 Behind the Screens: Nursing, Somology, and the Problem of the Body. Churchill Livingstone, Melbourne

Lo R 2002 Evaluation of a Mentor-Arranged Clinical Practice Placement. Collegian 9: 27-32

Manfredi S, Canziani M, Draibe S, Dalboni M, Andreolli M, Watanabe R, Cendoroglo M 2003 A model for improving quality in nephrology settings. Nephrology nursing Journal 30: 295-299

Neary M 2000 Supporting students' learning and professional development through the process of continuous assessment and mentorship. Nurse Education Today 20: 463-474

Neary M, Phillips R, Davies B 1996 The introduction of mentorship to Project 2000 in Wales. Nursing Standard 10: 37-39 
Pulsford D, Boit K, Owen S 2000 Are mentors ready to make a difference? A survey of mentors' attitudes towards nurse education. Nurse Education Today 22: $439-446$

Secrest J, Norwood B, Keatley V 2003 "I was actually a nurse": The meaning of professionalism for baccalaureate nursing students. Journal of Nursing Education 42: $77-82$

Spouse J 2001 Bridging theory and practice in the supervisory relationship: a sociocultural perspective. Journal of Advanced Nursing 33: 51 -522

Suen L, Chow F 2001 Students' perceptions of the effectiveness of mentors in an undergraduate nursing programme in Hong Kong. Journal of Advanced Nursing 36: 505-511

Watson N 1999 Mentoring today - the students' views. An investigative case study of pre-registration nursing students' experiences and perceptions of mentoring in one theory/practice module of the Common Foundation Programme on a Project 2000 course. Journal of Advanced Nursing 29: $254-262$

Watson S 2004 Mentor preparation: reasons for undertaking the course and expectations of the candidates. Nurse Education Today 24: 30-40

White A 2003 Clinical decision making among fourth-year nursing students: an interpretive study. Journal of Nursing Education 42: 113-120 